\title{
Ventilation tubes did not improve quality of life in persistent otitis media with effusion
}

Rovers MM, Krabbe PF, Straatman H, et al. Randomised controlled trial of the effect of ventilation tubes (grommets) on quality of life at age 1-2 years. Arch Dis Child 2001 Jan;84:45-9.

QUESTION: In young children with persistent otitis media with effusion (OME), is treatment with ventilation tubes more effective than a period of watchful waiting for improving quality of life?

\section{Design}

Randomised \{allocation concealed*\} $\uparrow$, unblinded,* controlled trial with 12 months of follow up.

\section{Setting}

13 hospitals in the Netherlands.

\section{Patients}

206 children who had persistent OME confirmed by tympanometry and otoscopy. 19 children (9.2\%) withdrew from the trial immediately after randomisation, leaving 187 children (mean age $19 \mathrm{mo}$ ) in the study sample. 176 children $(85 \%)$ completed follow up.

\section{Intervention}

Patients were allocated to ventilation tubes $(n=93)$ or watchful waiting $(\mathrm{n}=94)$.

\section{Main outcome measures}

Quality of life was measured using the TNO-AZL Infant Quality of Life questionnaire (TAIQOL) (46 items covering 13 domains; 9 domains were used in the analysis). Parent-child interaction was measured by using the Erickson scales, which include 5 child scales (affection, avoidance, compliance, negativism, and reliance) and 5 parent scales (supportive presence, respect, structure and limits, instruction, and hostility).

\section{Main results}

The study had power to detect a difference of 0.5 on a 12 point scale in improvement on the TAIQOL questionnaire between groups. At 12 months, quality of life improved in 6 domains (vitality, communication, motoric, social, eating, and sleeping) and deteriorated in 3 domains (appetite, anxiety, and aggression). The ventilation tube group showed no greater improvement or less deterioration than the watchful waiting group in any of the domains. A multivariate analysis of variance was done to detect evidence of a treatment effect for all domains combined and showed no difference between groups at 6 months $(\mathrm{p}=0.22)$ or 12 months $(\mathrm{p}=0.94)$. The groups did not differ for Erickson scores between baseline and 12 months. No treatment effect was seen for all domains combined for the child scales at 6 months $(p=0.19)$ or 12 months $(p=0.38)$ or for the parent scales $(\mathrm{p}=0.21$ and $\mathrm{p}=0.95$, respectively).

\section{Conclusion}

In young children with persistent otitis media with effusion detected by screening, treatment with ventilation tubes did not improve quality of life more than watchful waiting.

*See glossary.

†Information provided by author.

\section{COMMENTARY}

Recent randomised trials using the same patient sample as that of the study by Rovers $e t$ al and another cohort suggest that early placement of ventilation tubes offers no advantage in language and other developmental outcomes in young children. ${ }^{12}$ In the current study, Rovers et al report no effect of tubes on quality of life, yet other studies document a high rate of parental satisfaction with tube placement. ${ }^{34}$

A challenge of quality of life research is selection of the right measurement tool. Generic instruments like those used here are good for comparisons of different diseases, but for longitudinal changes in a given health condition, a disease specific measure may be more responsive. ${ }^{5}$

A multicentre before and after trial using the OM- 6 , a reliable and responsive quality of life measure of otitis media specific symptoms, showed a large improvement in such symptoms after tube placement. ${ }^{6}$ These results warrant a well designed randomised trial using the OM- 6 before we conclude that ventilation tubes have no beneficial effect on quality of life.

Michael B Aldous, MD, MPH University of Arizona College of Medicine Tucson, Arizona, USA

1 Rovers MM, Straatman H, Ingels K, et al. The effect of ventilation tubes on language development in infants with otitis media with effusion: a randomized trial. Pediatrics 2000; 106:e42.

2 Paradise JL, Feldman HM, Campbell TF, et al. Effect of early or delayed insertion of tympanostomy tubes for persistent otitis media on developmental outcomes at the age of three years. N Engl J Med 2001;344:1179-87.

3 Hughes LA, Wight ID. Tympanostomy tubes: long-term effects. Am Fam Physician 1988;38:186-90.

4 Facione N. Quality of life issues in chronic otitis media with effusion: parameters for future study. Int I Pediatr Otorhinolaryngol 1991;22:167-79.

5 Guyatt GH, Naylor CD, Juniper E, et al. Users' guides to the medical literature. XII. How to use articles about healthrelated quality of life. JAMA 1997;277:1232-7.

6 Rosenfeld RM, Bhaya MH, Bower CM, et al. Impact of tympanostomy tubes on child quality of life. Arch Otolaryngol Head Neck Surg 2000;126:585-92.
Source of funding: Dutch Investigative Medicine Fund of the National Health Insurance Board.

For correspondence: Dr M M Rovers, Department of Otorhinolaryngology, University Medical Centre Nijmegen, $P O$ Box 9101,6500 HB Nijmegen, the Netherlands. m.rovers@mie.kun.nl. 